\title{
Microscopic Structure Control of Carbon Nanofiller/Epoxy Composite by Using AC Electrical Field and the Effect on Physical Properties*
}

\author{
Yoshinobu SHIMAMURA**, Toshihiro CHIBA***, Naoki OKUDA**** \\ and Keiichiro TOHGO** \\ **Department of Mechanical Engineering, Shizuoka University, \\ 3-5-1 Johoku, Naka-ku, Hamamatsu, Shizuoka 432-8561, Japan \\ E-mail: tysimam@ipc.shizuoka.ac.jp \\ ***Toho Tenax Co., Ltd., \\ 37-19 Tadatsu-aza, Yoshinari, Oujin-cho, Tokushima, Tokushima 771-1153, Japan \\ **** Toray Industries, Inc., \\ 1515 Tsutsui, Matsumae, lyo-gun, Ehime 791-3193, Japan
}

\begin{abstract}
It is well known that carbon nanofillers (CNFs) enhance the stiffness, electrical conductivity and thermal conductivity of polymers. Alignment of carbon nanofillers in polymer is expected to increase the performances in the aligned direction. Several papers have reported that applying AC electrical field to liquid suspension including CNFs make CNFs align in the electrical field direction. In this paper, the microscopic structure of carbon nanofiller/epoxy composites was controlled by using AC electrical field, i.e. carbon nanofillers were aligned unidirectionally in resin. The alignment of CNFs was in-situ observed during fabrication by using an optical microscope, and the effects of applied voltage, frequency and the weight fraction of $\mathrm{CNFs}$ on microscopic structure were investigated. Furthermore, thermal conductivity, electrical conductivity and mechanical properties of composites were measured. The results show that CNFs in uncured epoxy resin align in the AC field direction and form a chain-like network, and that the applied voltage and weight fraction affect the morphology of the chain-like network. Unidirectional alignment enhances the thermal and electrical conductivities, and affects mechanical properties.
\end{abstract}

Key words: Carbon Nanofiller, Composites, AC Electrical Field, Microscopic Structure Control, Conductive Properties, Mechanical Properties

\section{Introduction}

It is well known that carbon nanofillers (CNFs) enhance the stiffness, electrical conductivity and thermal conductivity of polymers ${ }^{(1)}$. Alignment of carbon nanofillers in polymer is expected to increase the performances in the aligned direction. Several methods are known to align carbon nanofillers in matrix ${ }^{(2)}$. Resin flow $^{(3)-(5)}$ and magnetic field ${ }^{(6)-(10)}$ are often used for alignment, but the former method may not control the alignment direction and the latter method requires at least several $\mathrm{T}$ of magnetic field, which is significantly large and needs superconductive coils. Several papers have reported that applying alternating current $(\mathrm{AC})$ electrical field to a liquid suspension including $\mathrm{CNFs}$ causes alignment of CNFs in the electrical field direction ${ }^{(11)-(13)}$. Prasse et al. ${ }^{(14,15)}$ have reported 
the fabrication of microscopic structural controlled composites by using AC electrical field. The advantage of this method is the possibility to align CNFs in the through-thickness direction. That may enhance the through-thickness properties of continuous fiber reinforced composite laminates. In addition, the required level of AC electrical field is a few hundreds to thousands $\mathrm{V} / \mathrm{cm}$. It is easy to apply such $\mathrm{AC}$ electrical field to a thin plate. The conditions to make CNFs align and the physical properties of composites with microscopic control have not been fully investigated.

In this study, unidirectional aligned carbon nanofiller/epoxy composites were fabricated under AC electrical field, and the alignment of CNFs was in-situ observed during fabrication by using an optical microscope. The effects of applied voltage, frequency and the weight fraction of CNFs on microstructure were investigated. As a result, it was found that CNFs in uncured epoxy resin align in the $\mathrm{AC}$ field direction and form a chain-like network, and that the applied voltage and weight fraction affect the morphology of the network. In addition, physical properties of composite plates cured under AC electrical field were measured. Three types of CNFs were used to fabricate the composite plates. Alignment enhanced the thermal and electrical conductivities and the type of CNF affected these conductivities, and also affected the tensile mechanical properties.

\section{In-Situ Observation of Alignment Process}

In order to investigate the behavior of CNFs in epoxy cured under AC electrical field, in-situ observation was carried out by using an optical microscope. VGCF (carbonized, Showa Denko K.K.) was chosen as filler and General Purpose Epoxy Resin (System Three Resins, Inc.) was chosen as resin. VGCF is a kind of multi-wall carbon nanotube (MWNT), and the diameter is $120 \mathrm{~nm}$ and the length is $10 \mu \mathrm{m}$. The epoxy consists of diglycidyl ether of bisphenol $\mathrm{A}>70 \%$ and alkylglycidyl ether $<30 \%$, and the curing agent consists of modified aliphatic amines $50-70 \%$ and nonyl phenol $30-50 \%$. The epoxy resin cures at room temperature, and the working time at $25{ }^{\circ} \mathrm{C}$ is $60 \mathrm{~min}$. The viscosities of epoxy and curing agent are $550 \mathrm{mPa} \cdot \mathrm{s}$ and $350 \mathrm{mPa} \cdot \mathrm{s}$, respectively.

VGCF of $0.13 \mathrm{wt} \%$ and epoxy with curing agent were mixed by using a planetary mixer for 10 min. The VGCF suspension was dropped on a parallel electrode that was coated with a thin polyvinyl alcohol film for insulation. The electrode spacing was $500 \mu \mathrm{m}$. The parallel electrode is shown in Figure 1. During cure, AC square-wave electrical field of $500 \mathrm{~V} / \mathrm{cm}$ at $1 \mathrm{kHz}$ was applied.

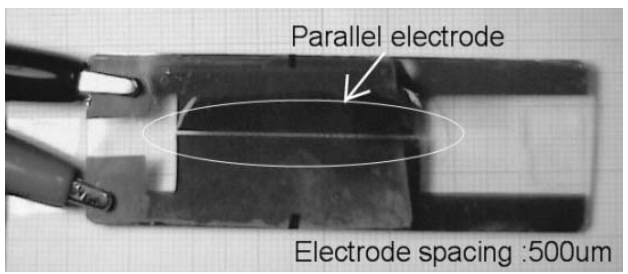

Fig. 1 Parallel electrode for in-situ observation of CNF alignment by using AC electrical field

Figure 2 shows the micrographs during cure. The upper and lower black areas in micrographs are the parallel electrode, and thus the AC field direction is vertical. VGCFs and the agglomerations of VGCFs aligned in the AC field direction in several minutes (Fig.2(b)) and formed a chain-like network (Fig.2(c)), and in the end the network structure was hold by cured epoxy resin (Fig.2(d)).

Figure 3 shows possible mechanisms for aligning CNFs and forming a chain-like network. As soon as applying electrical field to CNF suspension, electrostatic induction of each VGCF occurs. Then, VGCFs align in the electrical field direction due to the moment 
induced by electrostatic induction, and agglomerate each other due to electrostatic force. The electrostatic induction occurs instantly because VGCF is expected to be conductor. Therefore, direct current (DC) electrical field and alternating current (AC) electrical field have, substantially, the same effect on the $\mathrm{VGCF}^{(15)}$.

In the case of applying DC electrical field, however, the unidirectional alignment of CNFs does not always occur because CNFs are charged in suspension and thus may migrate to one electrode ${ }^{(16,17)}$.

As a result, it is shown that unidirectional aligned carbon nanofiller composites can be fabricated by using AC electrical field.

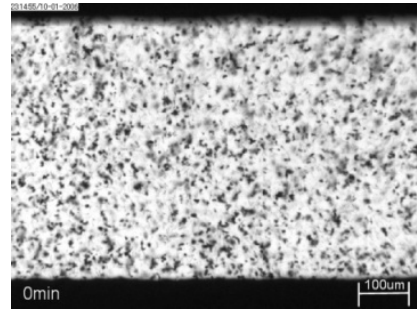

(a) 0 min

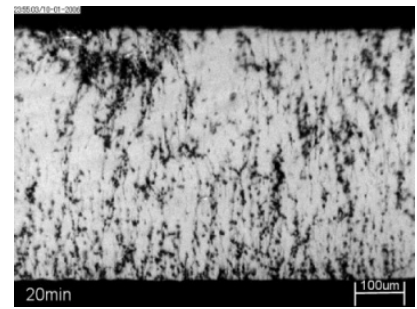

(c) $20 \mathrm{~min}$

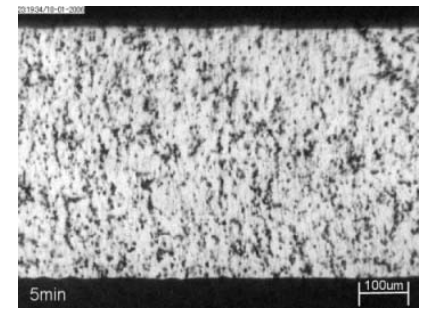

(b) $5 \mathrm{~min}$

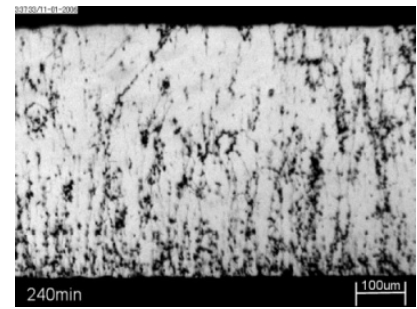

(d) After cure

Fig. 2 Alignment and chain-like network structure formation under AC electrical field

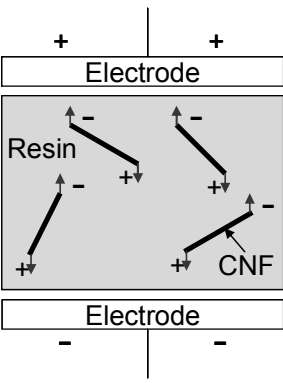

Electrostatic induction by $A C$ electrical field
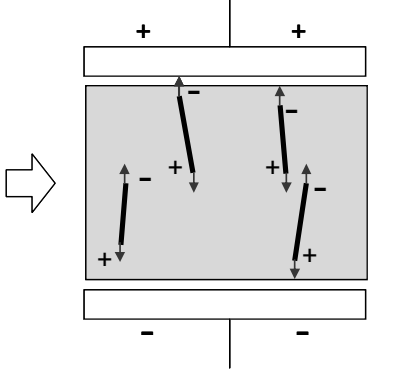

Alignment in the AC field direction

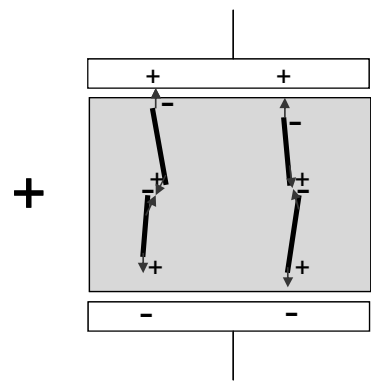

Network formation due to electrostatic force between CNTs

Fig. 3 Mechanisms of alignment and chain-like network formation

\section{Effect of Fabrication Parameters on Microscopic Structure}

Three fabrication parameters, the weight fraction of VGCF, the amplitude of AC electrical field and the frequency, were varied to investigate the effect of the three parameters on microstructure. For simplicity of experiments, VGCF suspensions without curing agent were used for in-situ observation. VGCF and epoxy without curing agent were mixed by using a planetary mixer for $10 \mathrm{~min}$ and then sonicated for $2 \mathrm{hr}$. 


\subsection{Effect of Weight Fraction of VGCF}

Suspensions with VGCF of 0.2, 0.4, 0.6, 0.8 and $1.0 \mathrm{wt} \%$ were in-situ observed under $1000 \mathrm{~V} / \mathrm{cm}$ of AC square-wave electrical field at $1 \mathrm{kHz}$. Figure 4 shows the microstructures at $20 \mathrm{~min}$. In the case of $0.2-0.6 \mathrm{wt} \%$ of VGCF, alignment of VGCFs in the electrical field was visible. For 0.8 and $1.0 \mathrm{wt} \%$, VGCFs did not seem to align.

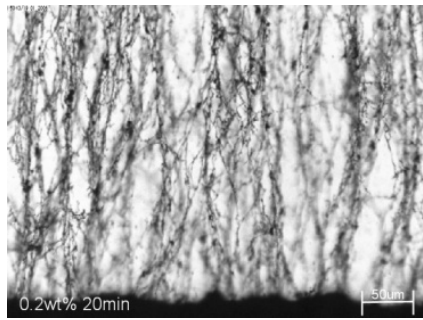

(a) $0.2 \mathrm{wt} \%$

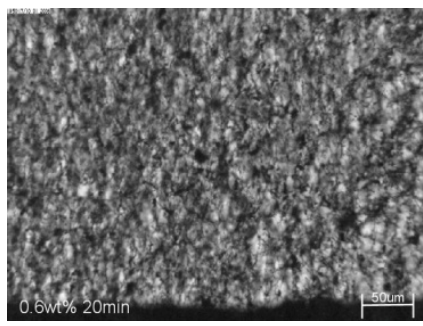

(c) $0.6 \mathrm{wt} \%$

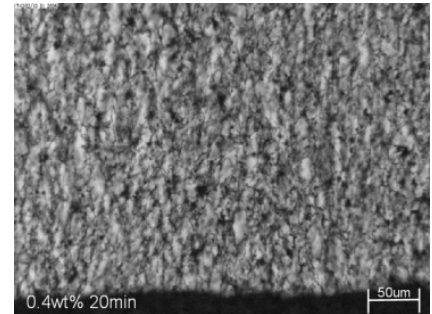

(b) $0.4 \mathrm{wt} \%$

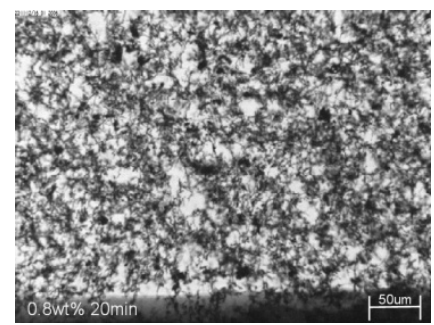

(d) $0.8 \mathrm{wt} \%$

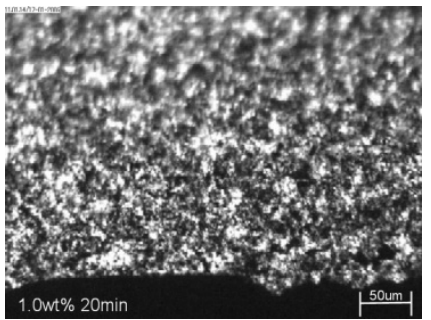

(d) $1.0 \mathrm{wt} \%$

Fig. 4 Microstructures for various weight fractions
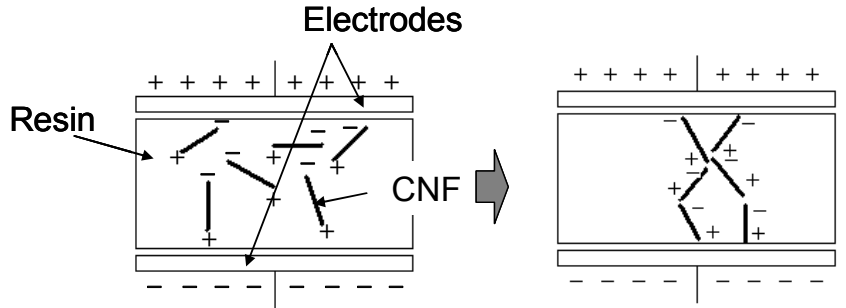

(a) Below the percolation threshold
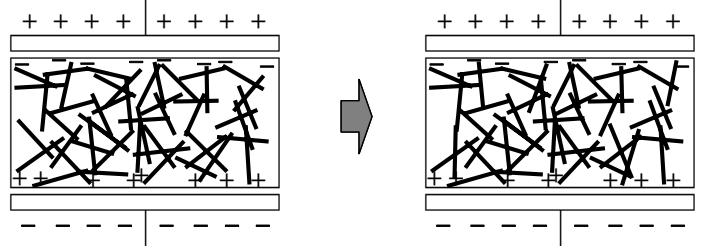

(b) Above the percolation threshold

Fig. 5 Electrostatic induction below and above the percolation threshold

In polymer composites containing conductive fillers such as CNF, it is well known that the electrical conductivity of the composites exhibits percolation behavior ${ }^{(18,19)}$. Since an 
electrical conductive path is formed in resin if the weight content of conductive fillers is higher than the percolation threshold, composites have conductivity above the percolation threshold, but do not have conductivity below the percolation threshold.

When the weight fraction is higher than the percolation threshold, which is usually less than a few $\%$, electrostatic induction of each VGCF is not able to occur because a conductive network already exists in resin as shown in Fig.5, and thus alignment and chain-like network formation does not occur. In other words, there is an upper limitation of the weight fraction for aligning carbon nanofillers by using AC electrical field.

\subsection{Effect of Amplitude of AC Electrical Field}

Suspensions with VGCF of $0.2 \mathrm{wt} \%$ were in-situ observed under 50 to $2000 \mathrm{~V} / \mathrm{cm}$ of AC square-wave electrical field at $1 \mathrm{kHz}$. Figure 6 shows the microstructures at $20 \mathrm{~min}$. In the case of $50 \mathrm{~V} / \mathrm{cm}, \mathrm{VGCFs}$ could not align. If $250 \mathrm{~V} / \mathrm{cm}$ or more of AC electrical field was applied, a chain-like network morphology was formed. Higher the amplitude was, faster the network formation was and coarser the chain-like network was. This is because the moment and electrostatic force between VGCFs induced by AC electrical field is larger if the amplitude of $\mathrm{AC}$ field is larger. This network morphology change may affect the macro properties of composites.

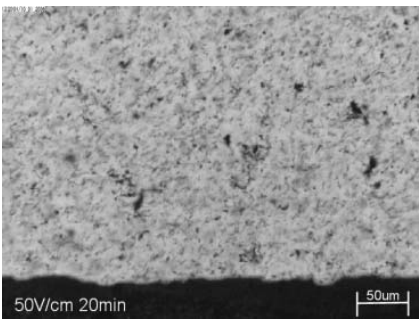

(a) $50 \mathrm{~V} / \mathrm{cm}$

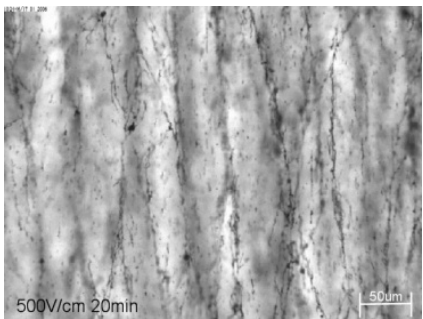

(c) $500 \mathrm{~V} / \mathrm{cm}$

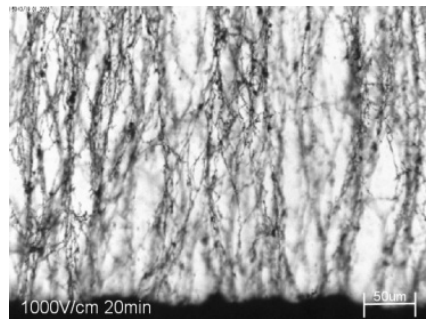

(e) $1 \mathrm{kV} / \mathrm{cm}$

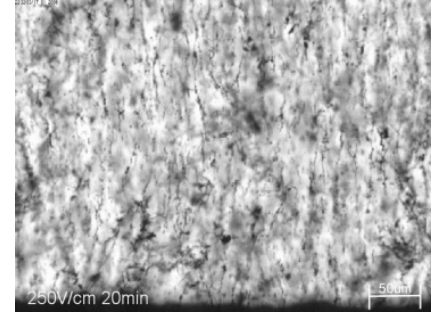

(b) $250 \mathrm{~V} / \mathrm{cm}$

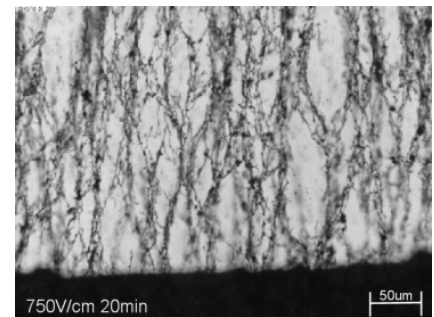

(d) $750 \mathrm{~V} / \mathrm{cm}$

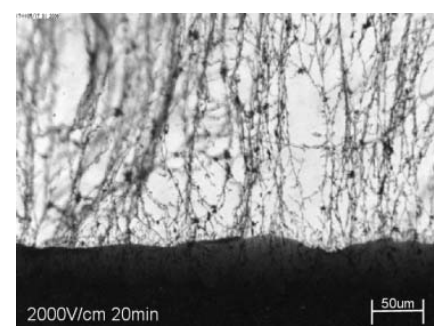

(f) $2 \mathrm{kV} / \mathrm{cm}$

Fig. 6 Microstructures for various applied voltages

\subsection{Effect of Frequency of AC Electrical Field}

Suspensions with VGCF of $0.2 \mathrm{wt} \%$ were in-situ observed under $1000 \mathrm{~V} / \mathrm{cm}$ of AC square-wave electrical field at $10,100,1 \mathrm{k}, 10 \mathrm{k}$, and $100 \mathrm{k} \mathrm{Hz}$. Figure 7 shows the microstructures at $20 \mathrm{~min}$. Regardless of the frequency except for less than $100 \mathrm{~Hz}$, the network morphologies are almost similar. The effect of applied frequency is smaller than those of the amplitude of AC electrical field and the weight fraction. In the case of low 
frequencies, coarser networks were formed. Since VGCF/epoxy suspension is pseudoplastic fluid ${ }^{(20)}$, this might facilitate the travel of VGCF in epoxy resin at low frequencies.

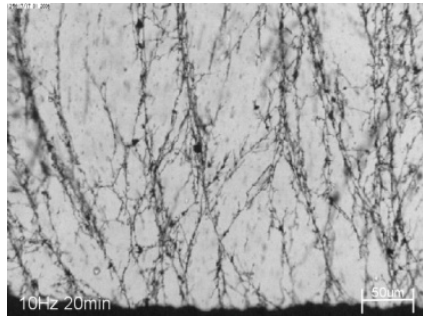

(a) $10 \mathrm{~Hz}$

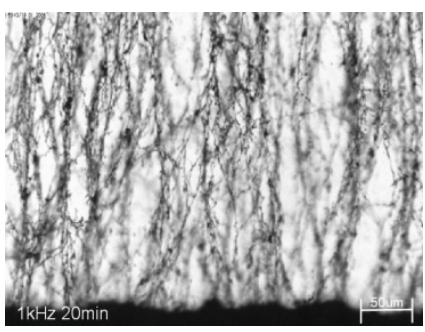

(c) $1 \mathrm{kHz}$

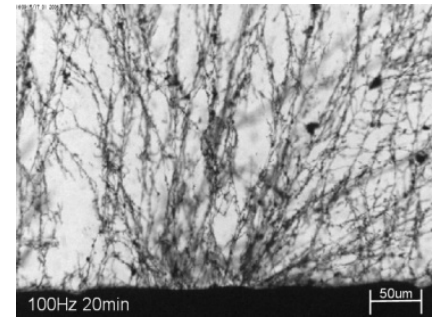

(b) $100 \mathrm{~Hz}$

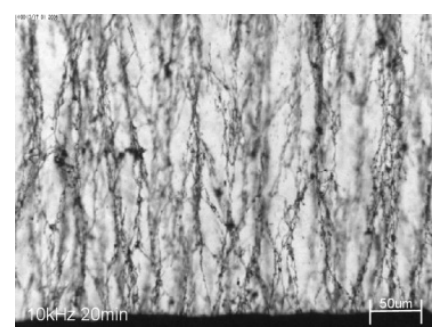

(d) $10 \mathrm{kHz}$

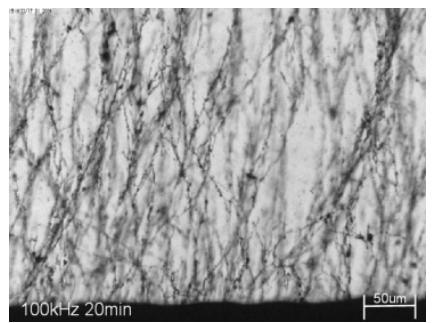

(e) $100 \mathrm{kHz}$

Fig. 7 Microstructures for various applied frequencies

\section{Material Properties of Composites with Microscopic Structure Control}

Thermal conductivity, DC electrical conductivity and mechanical properties of composites with and without microscopic structure control were measured to investigate the effect of the microscopic structure control by using AC electrical field.

\subsection{Materials}

Three types of CNF were used as filler: cup-stacked type carbon nanotube (CSCNT, GSI Creos Corp.) and two types of vapor grown carbon fibers with a different diameter (VGCF and VGCF-S, Showa Denko K.K.). CSCNT is composed of truncated conical graphene sheets. The truncated conical grapheme sheets are stacked. Thus, CSCNT has a large hollow core and open ends. VGCF and VGCF-S are kinds of MWCNT, and the diameters are $150 \mathrm{~nm}$ and $100 \mathrm{~nm}$, respectively. Table 1 shows the physical properties of the three types of CNF. A room temperature cured epoxy used in the aforementioned section was used as matrix. 
Table 1 Physical properties of CNFs.

\begin{tabular}{|c|c|c|c|}
\hline & CSCNT & VGCF & VGCF-S \\
\hline Diameter $[\mathrm{nm}]$ & $50-200$ & 150 & 100 \\
\hline Length $[\mu \mathrm{m}]$ & 20 & 10 & 9 \\
\hline Resistivity $[\Omega \mathrm{m}]$ & $5.5 \times 10^{-7}$ & $1 \times 10^{-6}$ & $1 \times 10^{-6}$ \\
\hline Thermal conductivity $[\mathrm{W} / \mathrm{mK}]$ & - & 1200 & 1200 \\
\hline
\end{tabular}

\subsection{Fabrication of Specimen}

In order to disperse CNFs in the epoxy resin, CNFs and epoxy resin (without curing agent) were mixed by using a planetary mixer for $20 \mathrm{~min}$. The suspension was sonicated for $1 \mathrm{hr}$ and then mixed with the curing agent by using a planetary mixer for $20 \mathrm{~min}$. The suspension was poured into a mold that was composed of a couple of copper plates coated by insulating polymer (polyvinyl alcohol) and a silicon rubber dam $(110 \times 110 \mathrm{~mm})$. The schematic is shown in Fig.8. Epoxy was cured for $6 \mathrm{hr}$ at $50{ }^{\circ} \mathrm{C}$ with $800 \mathrm{~V} / \mathrm{cm}$ of AC square-wave electrical field at $10 \mathrm{~Hz}$.

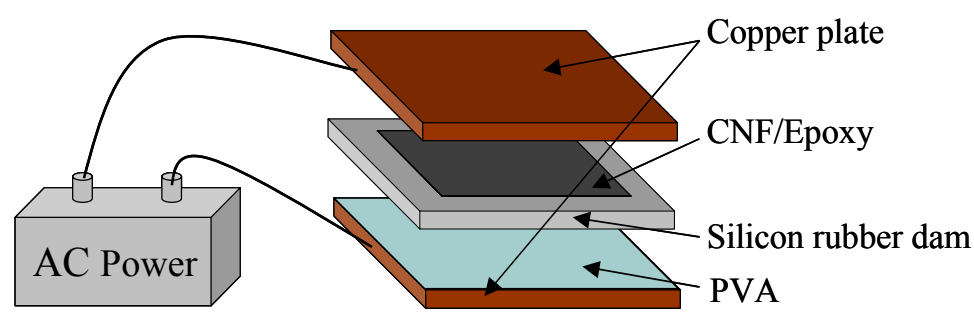

Fig. 8 Schematic of specimen molding.

In order to confirm the microstructures of composites cured under AC electrical field, thin pieces were sliced for optical microscopic observation. The micrographs for various weight fractions of three types of CNFs were shown in Figs.9-11. In the case of CSCNT, alignment and chain-like network formation of CSCNTs parallel to the AC field direction was visible for $0.5 \mathrm{wt} \%$ and $1.0 \mathrm{wt} \%$. CSCNTs were partly aligned for $1.5 \mathrm{wt} \%$ but did not seem to align for $2.0 \mathrm{wt} \%$. In the case of VGCF, alignment and network formation was observed for $0.5 \mathrm{wt} \%$ but did not seem to align for $1.0 \mathrm{wt} \%$ or above. In the case of VGCF-S, alignment and network formation was partly observed for $0.2 \mathrm{wt} \%$, but did not seem to align for $0.5 \mathrm{wt} \%$ or above.

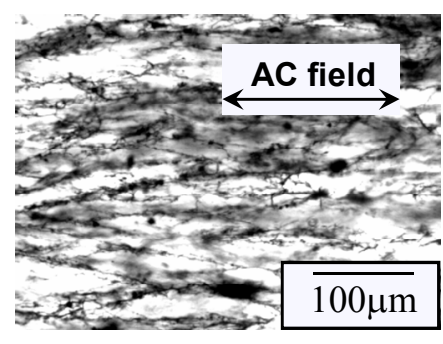

(a) $0.5 \mathrm{wt} \%$

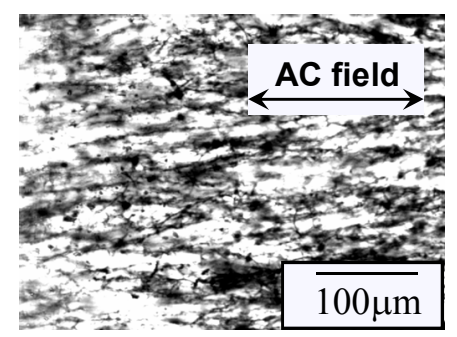

(b) $1.0 \mathrm{wt} \%$ 


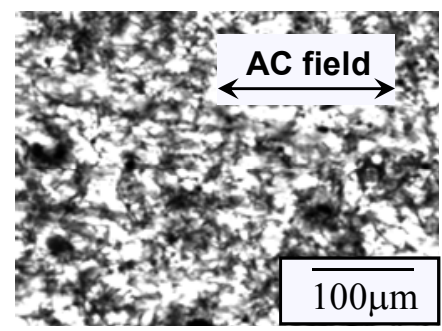

(c) $1.5 \mathrm{wt} \%$

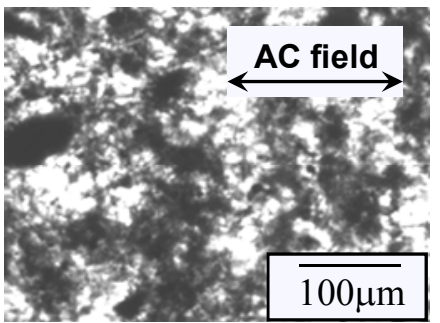

(d) $2.0 \mathrm{wt} \%$

Fig. 9 Micrographs of CSCNT/Epoxy composites.

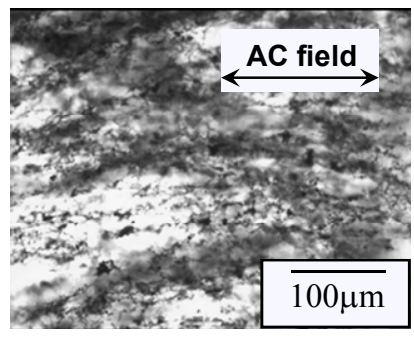

(a) $0.5 \mathrm{wt} \%$

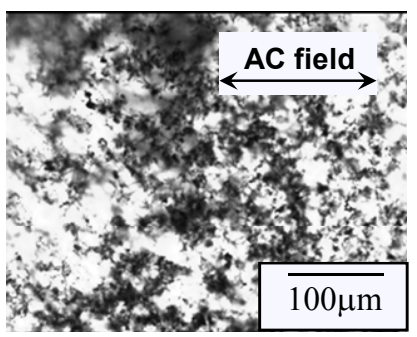

(b) $1.0 \mathrm{wt} \%$

Fig. 10 Micrographs of VGCF/Epoxy composites.

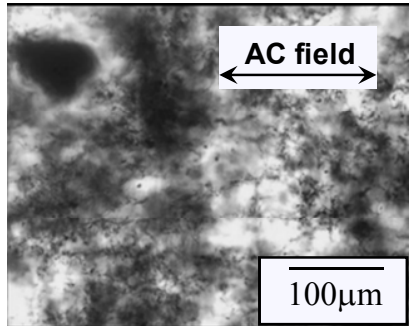

(a) $0.2 \mathrm{wt} \%$

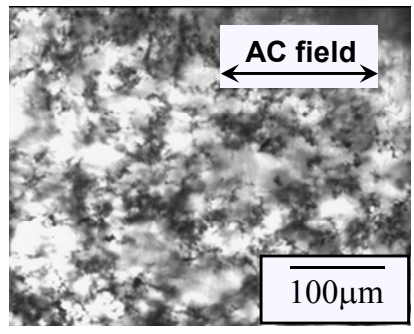

(b) $0.5 \mathrm{wt} \%$

Fig. 11 Micrographs of VGCF-S/Epoxy composite

As mentioned before, the weight fraction of CNF should be less than the percolation threshold to polarize each $\mathrm{CNF}$ by applying AC electrical field. A chain-like network of CSCNT was formed at higher filler weight contents because CSCNT has a higher percolation threshold than those of VGCF and VGCF-S, which will be shown in Sec.4.4. In contrast, it is difficult to align VGCF-S because the percolation threshold is lower than CSCNT and VGCF.

\subsection{Thermal Conductivity}

Four specimens $(30 \mathrm{~mm} \times 30 \mathrm{~mm})$ were cut from each CNF/Epoxy composite plate and the resin rich region of the surface was removed by sand paper. Thermal conductivity in the through-thickness direction, i.e. aligned direction, was measured by using the steady-state heat conduction method (TCM-30, Captec Enterprise). The specimens with $1 \mathrm{~mm}$ and $2 \mathrm{~mm}$ thick were prepared to eliminate contact thermal resistance between specimen and sensors. Figure 12 shows the measurement results of CSCNT/Epoxy composites, and Fig.13 shows the results of VGCF/Epoxy and VGCF-S/Epoxy composites. In both figures, hatched areas show the weight fractions that alignment by applying AC electrical field was visible. The vertical axis is the thermal conductivity and the horizontal axis is the weight fraction of $\mathrm{CNF}$ in each figure. The scatter band was determined by $5 \%$ of significance probability.

In Fig.12, there was no significant increase in thermal conductivity and no significant 
difference in thermal conductivities between specimens cured with and without AC electrical field. Since CSCNT has unconnected structure in the longitudinal direction, its thermal conductivity is low and thus the contribution of filler to improve thermal conductivity is low. Therefore, it was not evident whether alignment of CNF enhances thermal conductivity for CSCNT.

In contrast, the thermal conductivity increased by adding VGCF and VGCF-S and was enhanced by applying AC electrical field during cure. The enhancement was also achieved at the weight fractions that alignment was not clearly visible. This implies that not only perfectly alignment but also partly alignment may enhance the thermal conductivity.

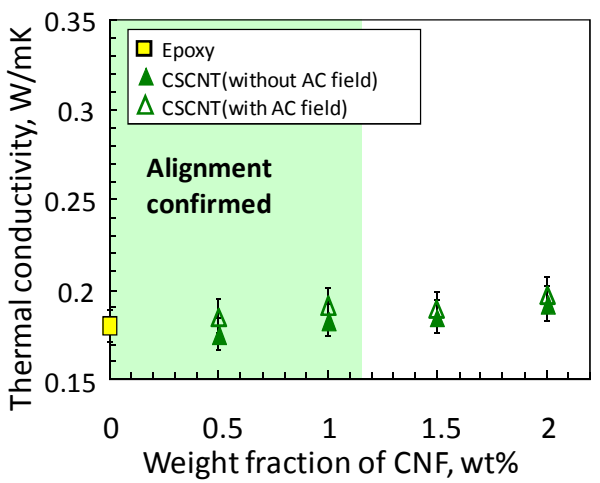

Fig. 12 Thermal conductivity of CSCNT/Epoxy composites

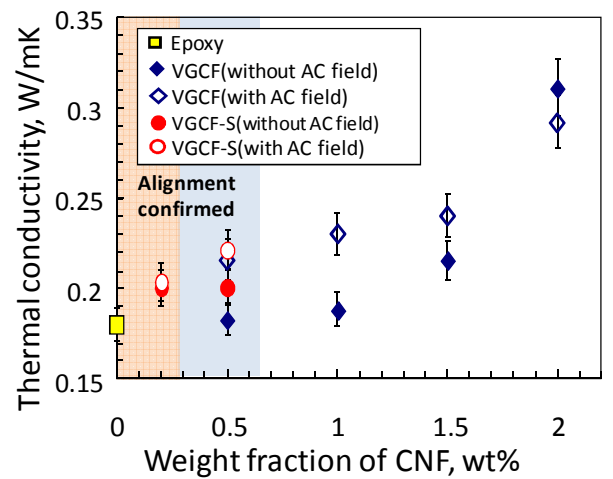

Fig. 13 Thermal conductivity of VGCF/Epoxy and VGCF-S/Epoxy composites

\subsection{Electrical Conductivity}

Upper and lower surfaces of the specimens used for measuring thermal conductivity were coated by silver paste and lead wires were attached to measure DC electrical resistance. The measurement results were shown in Figs.14-16. The vertical axis is the electrical resistivity and the horizontal axis is the weight fraction of CNFs. For CSCNT/Epoxy composite, the electrical resistances were not measurable for all specimens of $0.5 \mathrm{wt} \%$ and several specimens of $1.0 \mathrm{wt} \%$ cured without AC electrical field. In contrast, specimens with $0.5 \mathrm{wt} \%$ and $1.0 \mathrm{wt} \%$ cured under $\mathrm{AC}$ electrical field had electrical conductivity. This is because a conductive path was formed by AC electrical field. For VGCF/Epoxy composite, the electrical resistance of all specimens of $0.5 \mathrm{wt} \%$ cured without $\mathrm{AC}$ electrical field was not measurable, while all specimens of $0.5 \mathrm{wt} \%$ cured under $\mathrm{AC}$ electrical field had electrical conductivity. Although alignment of VGCF was not clearly observed at $1.0 \mathrm{wt} \%$ and $1.5 \mathrm{wt} \%$, the electrical resistivities of the specimens cured under $\mathrm{AC}$ electrical field were lower than those of the specimens cured without AC electrical field. This is probably because additional conductive paths were formed by AC electrical 
field in regions with low filler contents. For VGCF-S/Epoxy composite, all specimens showed electrical conductivity regardless of $\mathrm{AC}$ electrical field during cure. For $0.2 \mathrm{wt} \%$, the electrical resistance of specimens cured under $\mathrm{AC}$ electrical field was lower than that without AC electrical field.

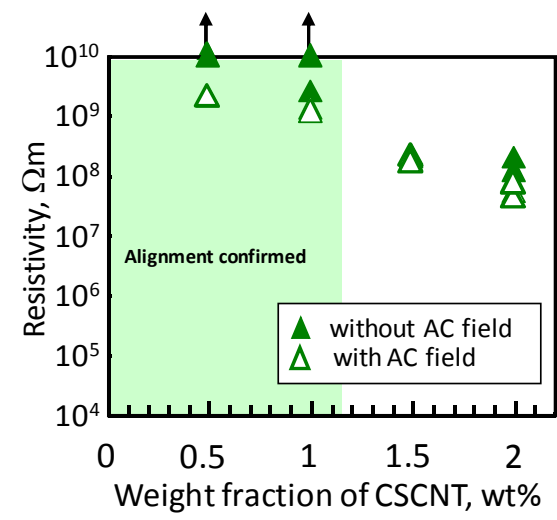

Fig. 14 Resistivity of CSCNT/Epoxy composite

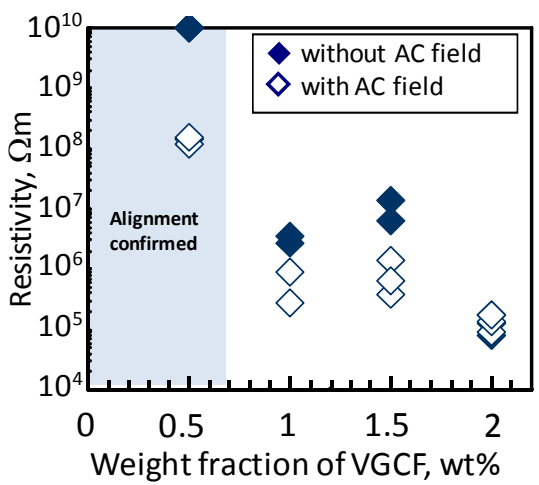

Fig. 15 Resistivity of VGCF/Epoxy composite.

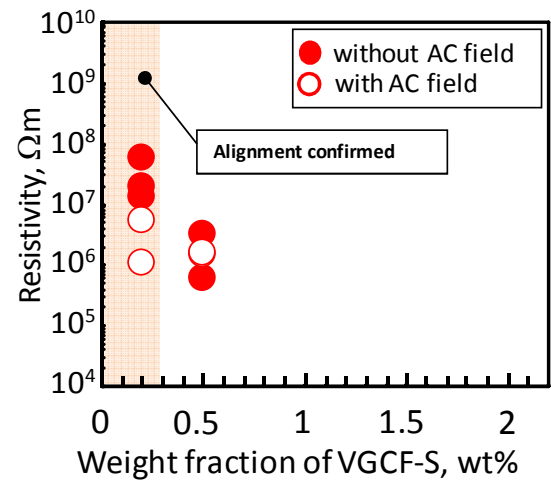

Fig. 16 Resistivity of VGCF-S/Epoxy composite.

\subsection{Tensile Test}

Tensile tests based on JIS 7113 were conducted to investigate the effect of alignment on mechanical properties. The specimen shape was rectangular with $100 \mathrm{~mm}$ long, $20 \mathrm{~mm}$ wide and $2 \mathrm{~mm}$ thick. Aluminum tabs were attached to each specimen and strain gauges were mounted on both surfaces of each specimen. The cross-head rate was $2 \mathrm{~mm} / \mathrm{min}$. The aligned direction of CNF was in the through-thickness direction and was normal to the loading direction as shown in Fig.17; the aim of tensile tests was just to confirm the effect of alignment on the mechanical properties. VGCF was used as filler for tensile tests because VGCF was supposed to have higher mechanical properties than CSCNT and VGCF could be easily mixed with epoxy resin than VGCF-S. 
Figure 18 shows stress-strain curves. Figure 19 and Fig.20 show Young's modulus and Tensile strength, respectively. Tensile strength is defined as the peak stress in a stress-strain curve. The difference of stress-strain curves is especially large for $0.5 \mathrm{wt} \%$, at which VGCFs were clearly aligned by applying AC electrical field. The results indicate that the microscopic structure change due to AC electrical field may affect mechanical properties such as Young's modulus and tensile strength.

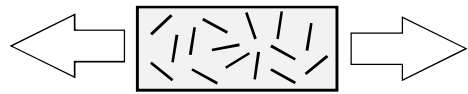

Randomly distributed (i.e. cured without AC field)

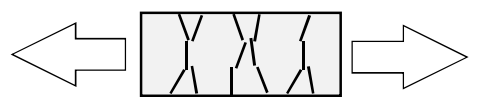

Unidirectionally aligned (i.e. cured with AC field)

Fig. 17 Loading direction

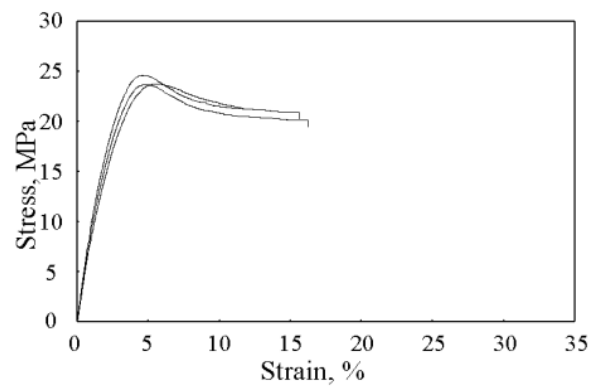

(a) Epoxy

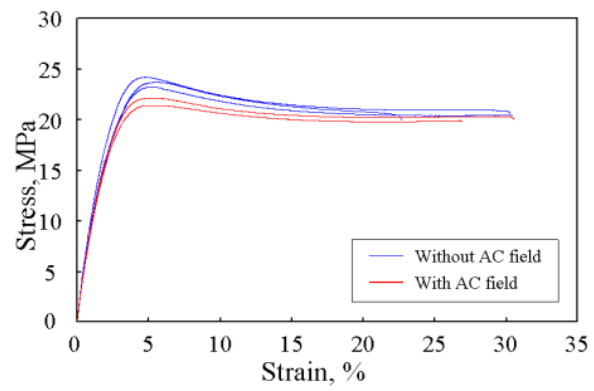

(c) $1.0 \mathrm{wt} \%$

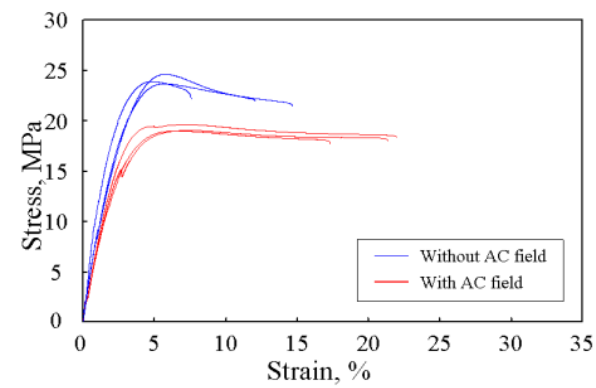

(b) $0.5 \mathrm{wt} \%$

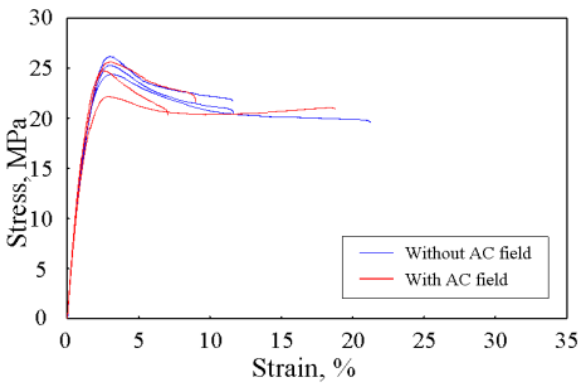

(d) $1.5 \mathrm{wt} \%$

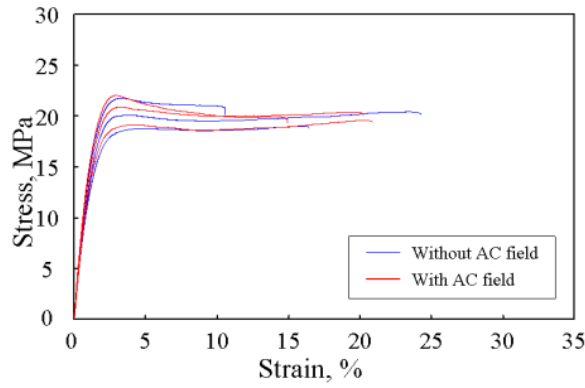

(e) $2.0 \mathrm{wt} \%$

Fig. 18 Stress-strain curves 


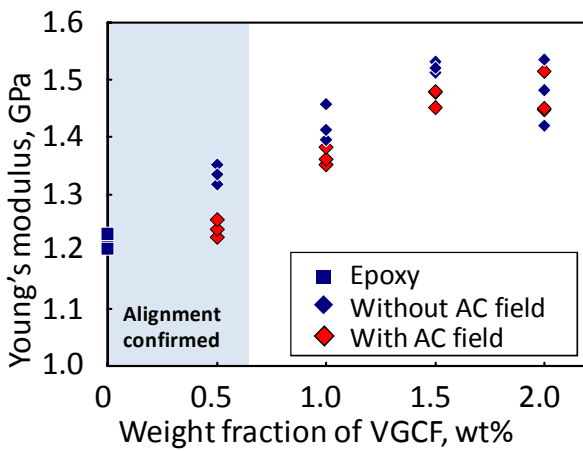

Fig. 19 Young's modulus

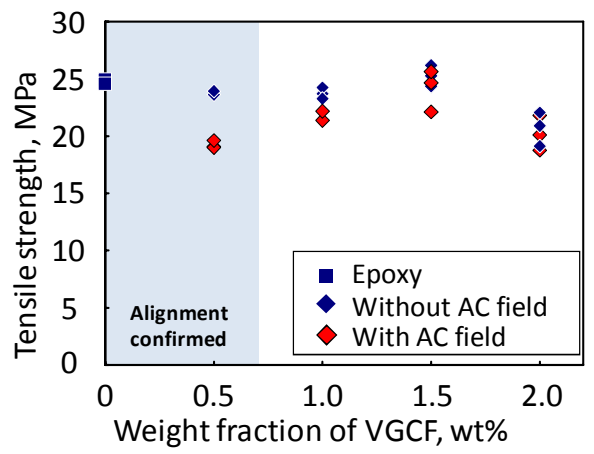

Fig. 20 Tensile strength

\section{Conclusions}

In this study, unidirectional aligned carbon nanofiller/epoxy composites were fabricated under $\mathrm{AC}$ electrical field, and the alignment of CNFs was in-situ observed during fabrication by using an optical microscope. The effects of applied voltage, frequency and the weight fraction of CNFs on microstructure were investigated. As a result, it was found that CNFs in uncured epoxy resin align in the AC electrical field and form a chain-like network, and that the applied voltage and weight fraction affect the morphology of the network.

Three types of unidirectionally aligned CNF/Epoxy composites were fabricated under $\mathrm{AC}$ electrical field, and the thermal conductivity and electrical conductivity were measured. Tensile mechanical properties of VGCF/Epoxy composites were also measured. As a result, it was found that alignment enhances the thermal conductivity for VGCF and VGCF-S and electrical conductivity for all CNFs used in this study, and that alignment also affects the tensile mechanical properties.

\section{References}

(1) Thostenson, E. T., Ren, Z. and Chou, T. W., Advances in the Science and Technology of Carbon Nanotubes and Their Composites: A Review, Composites Science and Technology, Vol.61 (2001), pp.1899-1912.

(2) Xie, X. L., Mai, Y. W. and Zhou, X. P., Dispersion and Alignment of Carbon Nanotubes in Polymer Matrix: A Review, Materials Science and Engineering R, Vol.49, No.4 (2005), pp.89-112.

(3) Enomoto, K., Yasuhara, T., Ohtake, N. and Kato, K., Injection Molding of Polystyrene Matrix Composites Filled with Vapor Grown Carbon Fiber, JSME International Journal Series A, Vol.46, No.3 (2003), pp.353-358.

(4) Haggenmueller, R., Zhou, W., Fischer, J. E. and Winey, K. I., Production and Characterization of Polymer Nanocomposites with Highly Aligned Single-Walled Carbon Nanotubes, Journal of Nanoscicence and Nanotechnology, Vol.3, No.1/2 (2003), pp.105-110.

(5) Kim, Y. A., Hayashi, T., Endo, M., Gotoh, Y., Wada, N. and Seiyama, J., Fabrication of Aligned Carbon Nanotube-Filled Rubber Composite, Scripta Materialia, Vol.54 (2006), pp.31-35.

(6) Kimura, T., Ago, H., Tobita, M., Ohsima, S., Kyotani, M. and Yumura, M., Polymer Composites of Carbon Nanotubes Aligned by a Magnetic Field, Advanced Materials, Vol.14, No.19 (2002), pp.1380-1383.

(7) Casavant, M. J., Walters, D. A., Schmidt, J. J. and Smalley, R. E., Neat Macroscopic Membranes of Aligned Carbon Nanotubes, Journal of Applied Physics, Vol.93, No.4 
(2003), pp.2153-2156.

(8) Fischer, J. E., Zhou, W, Vavro, J, Llaguno, M. C., Guthy, C., Haggenmueller, R., Casavant, M. J., Walters, D. E. and Smalley, R. E., Magnetically Aligned Single Wall Carbon Nanotube Films: Preferred Orientation and Anisotropic Transport Properties, Journal of Applied Physics, Vol.93, No.4 (2003), pp.2157-2163.

(9) Choi, E. S., Brooks, J. S., Eaton, D. L., Al-Haik, M. S., Hussaini, M. Y., Garmestani, H., Li, D. and Dahmen, K., Enhancement of Thermal and Electrical Properties of Carbon Nanotube Polymer Composites by Magnetic Field Processing, Journal of Applied Physics, Vol.64, No.9 (2003), pp.6034-6039.

(10) Takahashi, T., Murayama, T., Higuchi, A., Awano, H. and Yonetake, K., Aligning Vapor-Grown Carbon Fibers in Polydimethylsiloxane Using Dc Electric or Magnetic Field, Carbon, Vol.44 (2006), pp.1180-1188.

(11) Chen, X. Q., Saito, T., Yamada, H. and Matsushige, K., Alignment Single-Wall Carbon Nanotubes with an AC-Cuurent Electric Field, Applied Physics Letters, Vol.78, No.23 (2001), pp.3714-3716.

(12) Hilding, J. M., Hong, M. P. L. and Grulke, E. A., Alignment of Dispersed Multiwalled Carbon Nanotubes in Low Strength Ac Electrical Fields, Journal of Nanoscience and Nanotechnology, Vol.5, No.5 (2005), pp.742-746.

(13) Yang, X., Zhu, Y., Ji, L., Zhang, C. and Liang, J., Influence of Ac Electric Field on Macroscopic Network of Carbon Nanotubes in Polystyrene, Journal of Dispersion Science and Technology, Vol.28 (2007), 1164-1168.

(14) Prasse, T., J-Y. Cavaillé and W. Bauhofer, Electric Anisotropy of Carbon Nanofibre/Epoxy Resin Composites Due to Electric Field Induced Alignment, Composites Science and Technology, Vol.63 (2003), pp.1835-1841.

(15) Martin, C. A., Sandler, J, K. W., Windle, A. H., Schwarz, M.-K., Bauhofer, W., Schulte, K. and Shaffer, M. S. P., Electric Field-Induced Aligned Multi-Wall Carbon Nanotube Networks in Epoxy Composites, Polymer, Vol.46 (2005), pp.877-886.

(16) Yamamoto, K., Akita, S. and Nakayama, Y., Orientation of Carbon Nanotubes Using Electrophoresis, Japanese Journal of Applied Physics, Vol.35 (1996), pp.L917-L918.

(17) Koratkar, N., Modi, A., Kim, J., Wei, B. Q., Vajtai, R., Talapatra, S. and Ajayan, P. M., Mobility of Carbon Natubes in High Electric Field, Journal of Nanoscience and Nanotechnology, Vol.4, No.1/2 (2004), pp.69-71.

(18) Finegan, I. C. and Tibbetts, G. G., Electrical Conductivity of Vapor-Grown Carbon Fiber/Thermoplastic Composites, Journal of Materials Research, Vol.16, No.6 (2001), pp.1668-1674.

(19) Martin, C. A., Sandler, J. K. W., Shaffer, M. S. P., Schwarz, M. -K., Bauhofer, W., Schulte, K. and Windle, A. H., Formation of Percolating Networks in Multi-Wall Carbon Nanotube-Epoxy Composites, Composites Science and Technology, Vol.64 (2004), pp.2309-2316.

(20) Rahatekar, S. S., Koziol, K. K. K., Butler, S. A., Elliott, J. A., Shaffer, M. S. P., Mackley, M. R. and Windle, A. H., Optical Microstructure and Viscosity Enhancement for an Epoxy Resin Matrix Containing Multiwall Carbon Nanotubes, Journal of Rheology, Vol.50, No.5 (2006), pp.599-610. 